\title{
Author Response: Isolated Spontaneous Primary Tubercular Erector Spinae Abscess: A Case Report and Review of Literature
}

\author{
Bhavuk Garg, Chaitanya Dev Pannu, Rishi Ram Poudel, Vivek Morey \\ Department of Orthopedics, All India Institute of Medical Sciences, New Delhi, India
}

We appreciate readers for providing their insightful comments and detailed clarification on our article. They have drawn our attention towards the case reported by Indudhara et al. [1]. In our article we have mentioned that there exists one report [2] on isolated spontaneous primary tubercular erector spinae abscess until date. In our report, the usage of the word primarily signifies this case is important because it is 'primary' tubercular erector spinae abscess without any predisposing conditions such as immunocompromised state, any steroid or other drugs intake and presence of tuberculosis at any other body parts. We would like to mention here that the case reported by Indudhara et al. [1] was on renal transplant recipient with tubercular pyomyositis of left erector spinae muscle. This is totally a different case scenario from our case [3], as patient was a renal transplant recipient and had immunocompromised status. It has already been documented in the literature that risk of dissemination and extraskeletal tuberculosis is more in immunocompromised patients [4]. In our case [3], the patient was immunocompetent young female, who had spontaneous onset of lower back pain. Moreover, our case signifies that magnetic resonance imaging is non-invasive diagnostic modaltiy of choice in such cases as it gives much better details of the diseases affecting soft tissues.

We do agree that injection of muscular tissue by the tubercular bacilli without coexistence of active skeletal and extraskeletal tuberculosis is an event of rare occurrence. However, anti-tubercular multi drug therapy with or without surgical intervention (aspiration/incision and drainage) is the treatment of choice and has shown consistent results in the past [1-3,5].

We do appreciate the interest, which our readers have shown in our work and stressed appropriately for the awareness in the medical fraternity about the diagnosis and treatment of musculo-skeletal tuberculosis, as it is quite a rare entity in present world medical practice.

\section{Conflict of Interest}

No potential conflict of interest relevant to this article was reported.

\section{References}

1. Indudhara R, Singh SK, Minz M, Yadav RV, Chugh KS. Tuberculous pyomyositis in a renal transplant recipient. Tuber Lung Dis 1992;73:239-41.

2. Elshafie KT, Al-Hinai MM, Al-Habsi HA, Al-Hattali MS, Hassan O, Al-Sukaiti R. A massive tuberculosis abscess at the erector spinae muscles and subcutaneous tissues in a young man. Sultan Qaboos Univ Med

Received May 31, 2015; Accepted June 1, 2015

Corresponding author: Chaitanya Dev Pannu

Department of Orthopedics, All India Institute of Medical Sciences, New Delhi 110029, India

Tel: +91-11-2659-3550, Fax: +91-99-6803-7279, E-mail: cdpannu@gmail.com 
J 2013;13:601-5.

3. Garg B, Pannu CD, Poudel RR, Morey V. Isolated spontaneous primary tubercular erector spinae abscess: a case report and review of literature. Asian Spine J 2015;9:276-80.

4. Nissapatorn V, Kuppusamy I, Josephine FP, Jamaiah
I, Rohela M, Khairul Anuar A. Tuberculosis: a resurgent disease in immunosuppressed patients. Southeast Asian J Trop Med Public Health 2006;37 Suppl 3:153-60.

5. Metoui L, Ajili F. Abscess of the thigh: think of tuberculosis. Pan Afr Med J 2013;16:32. 